\title{
Aqueous foams stabilized with silica nanoparticle and alpha olefin sulfonates surfactant
}

\author{
T. A. T. Mohd ${ }^{1,2 *}$, N. F. Abu Bakar' ${ }^{1}$ N. Awang ${ }^{1}$ and A. A. Talib ${ }^{1}$ \\ ${ }^{1}$ Faculty of Chemical Engineering, Universiti Teknologi MARA \\ 40450 Shah Alam, Selangor, Malaysia. \\ ${ }^{2}$ School of Chemical and Energy Engineering, Faculty of Engineering \\ Universiti Teknologi Malaysia, Skudai \\ 81310 Johor Bahru, Johor, Malaysia. \\ Phone: +60355436302 ; Fax: +60355436300 \\ *Email: amran865@salam.uitm.edu.my
}

\begin{abstract}
Carbon dioxide $\left(\mathrm{CO}_{2}\right)$ foams have been introduced to improve mobility of $\mathrm{CO}_{2}$ in $\mathrm{CO}_{2}$ flooding. However, using surfactant alone to stabilize $\mathrm{CO}_{2}$ foam has potential weaknesses such as high surfactant retention in porous media and the foam is thermodynamically unstable for a long-term. Nanoparticle has been an alternative in stabilizing $\mathrm{CO}_{2}$ foam longer. This study aims to analyze $\mathrm{CO}_{2}$ foam stability at varying concentrations of surfactant, silica nanoparticle (SNP) and brine. The additions of SNP in anionic surfactant of alpha olefin sulfonates (AOS)-water and in AOS-brine towards foam stability were demonstrated in this study. $\mathrm{CO}_{2}$ foam stability was measured through the foam height observation and bubble size analysis. The performance of SNP and AOS suspensions in stabilizing foam were observed at different concentrations of AOS $(0.1,0.3$ and 0.5 $\mathrm{wt} \%)$, SNP (0.1, 0.3 and $0.5 \mathrm{wt} \%)$ and brine $(0.1,1$ and $5 \mathrm{wt} \%)$. The results revealed that the $\mathrm{CO}_{2}$ foams were most stable at $0.3 \mathrm{wt} \%$ SNP suspension in $0.5 \mathrm{wt} \%$ AOS-water. It was found that the most stable foams formed at concentration of $1 \mathrm{wt} \%$ of brine. Smaller and uniform bubble size has been produced at $0.3 \mathrm{wt} \% \mathrm{SNP}$ in $0.5 \mathrm{wt} \%$ AOS solution. Thus, concentrations of surfactant, SNP and brine have significant effects on $\mathrm{CO}_{2}$ foam stability.
\end{abstract}

Keywords: Foam stability; enhanced oil recovery; alpha olefin sulfonate (AOS); silica nanoparticles (SNP).

\section{INTRODUCTION}

Foams have been widely used in a number of industrial applications such as floatation, food processing, personal care product, oil recovery and etc. [1]. $\mathrm{CO}_{2}$ floods have been used for decades in the oil industry as one of the method of enhanced oil recovery (EOR). Critical weakness of $\mathrm{CO}_{2}$ flooding is the poor volumetric sweep efficiency, leading to channeling of $\mathrm{CO}_{2}$ through high permeability layers [1]. Mobility of $\mathrm{CO}_{2}$ flowing through porous medium becomes low when $\mathrm{CO}_{2}$ is dispersed in surfactant solution to form surfactant-stabilized $\mathrm{CO}_{2}$ foam. $\mathrm{CO}_{2}$ foam has been investigated since 1960's to improve the sweep efficiency and oil recovery [2]. Foam consists of bubbles, which are aggregated and comprise of a relatively large volume of gas, dispersing in a continuous liquid phase. One of the simplest methods to generate foam is by mixing the gas and liquid in a closed container, which is then shaken. A low concentration of surfactant, which is purposely mixed energetically with a gas phase could also produce foam [3]. Several factors affecting the foam stability have been identified such as capillary suction, gravity drainage and 
surface elasticity [4]. Thus, surfactant plays important roles in order to maintain the stability and improve the property of the foam. A standard foam stability diagram has been patented by Klaus et al. [5], which presented the trend of foam stability tests. Foam lifetime could be divided into "foaming" and "decay" sections, consisting of three stages, namely stage I (no foam rupture), stage II (rupture and syneresis occur simultaneously) and stage III (only rupture remained).

In oil and gas industry, to prevent an early breakthrough into production, gas is often injected together with surfactant solution to generate viscous foam which can control the mobility of the gas, resulting in enhancing the sweep efficiency $[6,7]$. Besides reducing the mobility of $\mathrm{CO}_{2}$ gas for higher oil recovery, good and long-term stability in the reservoir is crucial for a foam flooding [8]. However, surfactant used in stabilizing the aqueous $\mathrm{CO}_{2}$ foam was found to be ineffective for largescale application. It has some potential weaknesses, where aqueous $\mathrm{CO}_{2}$ foam is a thermodynamically unstable system for a long-term because the stability of surfactant foams is difficult to maintain [1]. When aqueous $\mathrm{CO}_{2}$ foams contacts with resident oil under hightemperature reservoir conditions, surfactant tends to degrade before fulfilling their long-term duty [9]. In addition, surfactant adsorption in porous media results in high chemical consumption in $\mathrm{CO}_{2}$ foam flooding [1]. Unstable foam is generated by surfactant due to surfactant molecules that dynamically enter and leave the interface, leading to a short-term stabilization inside the reservoir [10]. In EOR, the foam stability could be potentially monitored using streaming potential measurement with permanent electrodes installed downhole [11], followed by its preliminary investigation in monitoring alkaline-surfactant-polymer (ASP) flooding employing the theory of electrical double layer (EDL) [12, 13].

Nano-science has provided an alternative method in stabilizing the aqueous $\mathrm{CO}_{2}$ foams by using silica nanoparticle [14]. Adding nanoparticles to the surfactant solutions can synergistically improve foam viscosity and stability $[15,16]$. Foams stabilized by nanoparticle have become interest among researchers these past few years [14]. Many research efforts have been given related to nanoparticle-stabilized air in water foams $[17,18,19]$. Small particles can stabilize foams in the absence of any other surface-active agent [1]. Nanoparticle can act in similar way as surfactant and stability of $\mathrm{CO}_{2}$ foams are depending on the particle size and concentration of suspension [20, 21]. AttarHamed et al. [22] demonstrated the synergistic effect of silica nanoparticle (SNP) incorporated with AOS in aqueous $\mathrm{CO}_{2}$ foam for three different sizes of SNP. They found that the bigger SNP at lower concentration could provide better effect on $\mathrm{CO}_{2}$ foam stability, while the smaller SNP at higher concentration generally can lead to higher stability. The stability of foams is influenced by accumulation of the particles at the interface, which could minimize the contact area between water and oil. The solubility of amorphous silica is dependent on the particle size and for very small particle, the solubility exceeds but falls as the particle increase in size [23]. Smaller particle size could increase the viscosity of nanofluid, resulting in higher oil recovery [24].

Xue et al. [25] have investigated the prospect and presence of polyelectrolytes in the foam system by analyzing the viscosities and stabilities of foams up to $0.98 \mathrm{CO}_{2}$ volume fraction. They have found that addition of partially hydrolyzed polyacrylamide (HPAM) polymer to the mixture of laurylamidopropyl betaine (LAPB) and SNPs has slowed down the lamella drainage and inhibited coalescence resulting in a 2-3 fold higher viscosity and finer bubbles of $\sim 20 \mu \mathrm{m}$ than in the case without polymer ( $70 \mu \mathrm{m}$ fine bubbles). Sing and Mohanty [26] have conducted oil displacement experiments in Berea cores and found that adding nanoparticles at low concentrations (0.3 wt $\%$ ) improved the foam stability and increased the mobility reduction factor by a factor of 2 in the absence of oil. Approximately 10\% incremental oil recovery has been achieved over water flood when using core floods with reservoir crude. Moreover, the addition of nanoparticles and viscoelastic surfactant (VES) to the AOS solution improved the foam mobility-reduction factor (MRF) and allowed extra oil production (8\% in the presence of nanoparticles, $15 \%$ by adding nanoparticles and VES) [27]. San et al. [28] studied the effect of different ions on nanosilicastabilized $\mathrm{CO}_{2}$-foam generation, who demonstrated stable foam as the synthetic produced water and nanosilica dispersion and $\mathrm{CO}_{2}$ flowed through a porous medium. Besides its potential application in 
EOR, nanoparticle provides significant contribution to heat transfer performance and improvement of thermal properties in ethylene glycol-based nanofluid utilizing titanium dioxide $\left(\mathrm{TiO}_{2}\right)$ nanoparticle [29], zink oxide $(\mathrm{ZnO})$ and $\mathrm{TiO}_{2}$ nanoparticles [30] and carbon nanotube (CNT) [31]. Zakaria et al. [32] have reviewed the potential of adopting nanofluid as an alternative coolant in polymer electrolyte membrane fuel cell (PEMFC) cooling systems, while $\mathrm{TiO}_{2}$ nanotubes were formed in fluorinated organic electrolyte, resulting in longer nanotubes with higher energy conversion efficiencies during photoelectrochemical [33].

Foams stabilized using silica nanoparticle and surfactant have received great attention because of the potential it has as well as it is more economical [1]. The stability of foams in the presence of oil become a major concern for foam flooding application in oil reservoirs, as it could lead to foam destabilization [34]. In order to achieve a good mobility control, it is crucial that the foams remain stable when it is in contact with oil. Therefore, this study focused on $\mathrm{CO}_{2}$ foam stabilized by silica nanoparticle and anionic AOS surfactant in the presence of brine at varying concentrations. The foam stability provided by addition of surfactant and nanoparticle has been analyzed via the reduction of foam height in the observation cell over time at different concentration of suspension as well as the bubble size analysis. This study provides a prospect in the relationship between SNP concentration and surfactant concentration with foam stability in order to predict the most stable foam. Those concentrations and foam stability could also be correlated with the foam bubble size. The brine effect on various surfactant concentrations for $\mathrm{CO}_{2}$ foam generation and stability will aid in selecting the relevant surfactant concentration, which is able to generate stable foam at particular reservoir salinity that could withstand the reservoir condition. Thus, the application in the real field could benefit the oil and gas industry in term of making this EOR process more efficient and economically viable.

\section{MATERIALS AND METHODS}

\section{Materials}

Chemicals used in this study were silica nanoparticle (SNP) with 20-30nm sizes, Alpha Olefin Sulfonates (AOS) surfactant and sodium chloride. The SNP and sodium chloride were purchased from Merck Sdn Bhd, while AOS was obtained from Shanghai Foreign Trade Enterprise Pudong Co ltd. The $\mathrm{CO}_{2}$ gas used in this study is similar to the industrial usage with maximum purity of 96\%. Different concentration of SNP (0.1, 0.3 and $0.5 \mathrm{wt} \%)$ and AOS (0.1, 0.3 and $0.5 \mathrm{wt} \%)$ were prepared with distilled water for the suspensions of SNP and AOS. The suspensions were continuously stirred for another 12 hours to attain adsorption equilibrium. While for the solution of brine and AOS, the same concentrations of AOS were prepared with brine $(0.1,1$ and $5 \mathrm{wt} \%)$. The solution was continuously stirred for 1 hour. The experiment was carried out at room temperature and no $\mathrm{pH}$ adjustment was made.

\section{$\mathrm{CO}_{2}$ Foam Generation and Stability Test}

Figure 1 shows a schematic diagram of the $\mathrm{CO}_{2}$ foams generation apparatus. Basically, the experimental set up consisted of observation cell (foam column) made of Perspex with a length of $60.0 \mathrm{~cm}$, gas and injection of solution inlet, valve as well as drainage outlet.

The foam stability test was conducted at room temperature and atmospheric pressure. The experiment started by injecting 500mL suspension of SNP and AOS into the system by using syringe pump model NE-400 (New Era Pump Systems Inc.) at constant flow rate of $3 \mathrm{ml} / \mathrm{min}$. Once the suspension filled in the observation cell reached the height of $38.0 \mathrm{~cm}$, valve $\mathrm{V} 3$ was closed. Valve $\mathrm{V} 1$ and $\mathrm{V} 2$ were opened to allow $\mathrm{CO}_{2}$ gas entering the observation cell. $\mathrm{CO}_{2}$ gas was injected into the system at constant flow rate of $10 \mathrm{~mL} / \mathrm{min}$. The gas was continuously injected until the reaction leads to generation of foam that filled the column. When the column was filled with foam, the gas injection was shut off once the desired foam height was achieved by immediately closing 
V1 and V2. The initial height of foams in observation cell was recorded immediately. The experiment was conducted for 1 hour for the foam to degenerate by taking the foam height every 10 minutes' interval in order to analyze the foam stability. The smaller the foam height reduction over time, the slower the foam degeneration, thus the higher the foam stability.

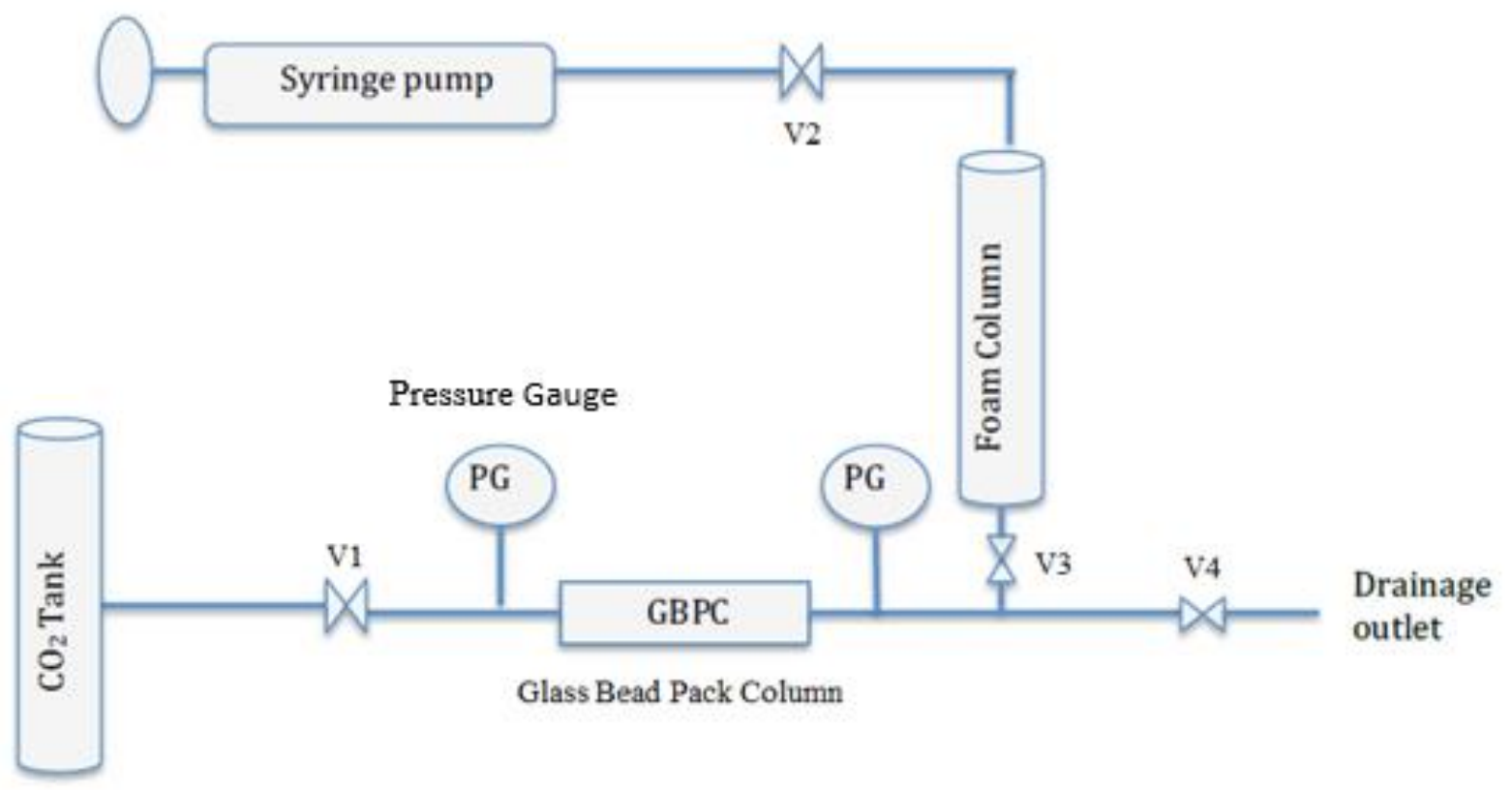

Figure 1. Schematic diagram of foam generation and stability experiment set up.

\section{Microscopy Observation for the Prepared Foams}

The prepared foam samples were place in petri dishes. The samples were then placed under a laboratory microscope (Olympus Microscope DP72 Digital Camera). Five samples of the same area or region of interest (ROI) of images were captured under the microscopes.

\section{Size Distribution Measurement}

Approximately 100 bubbles were selected from the captured images. The size of the captured bubbles was analysed using ImageJ software (version $1.47 \mathrm{v}$ ). The analysis required 24-bit image to be converted to 8-bit image for application of an edge detection algorithm. The average foam bubble size was extracted from the calibration of thresholding yields binary image using histogram equalization in order to minimize deference between the imaging procedures.

\section{RESULTS AND DISCUSSION}

\section{Foam Stability without and with Addition of SNP}

Basically, the smaller the foam height reduction over time, the slower the foam degeneration, thus the higher the foam stability. A standard foam stability phase and foam lifetime is shown in Figure 2, which could be divided into "foaming" and "decay" sections. There are three stages involved, namely stage I (no foam rupture), stage II (rupture and syneresis occur simultaneously) and stage III (only rupture remained). Foaming section is when the foam is generated and at its maximum height, which is the interval between the top of foam and liquid solution that is maintained until the 
deviation time, $t_{d e}$. Right after the deviation time, $t_{\text {de }}$, the liquid films inside foam begin to rupture. The half-life of foam with respect to its maximum height is known as the transition time, $\mathrm{t}_{\mathrm{tr}}$. The foam system is more stable when transition time is longer [5].

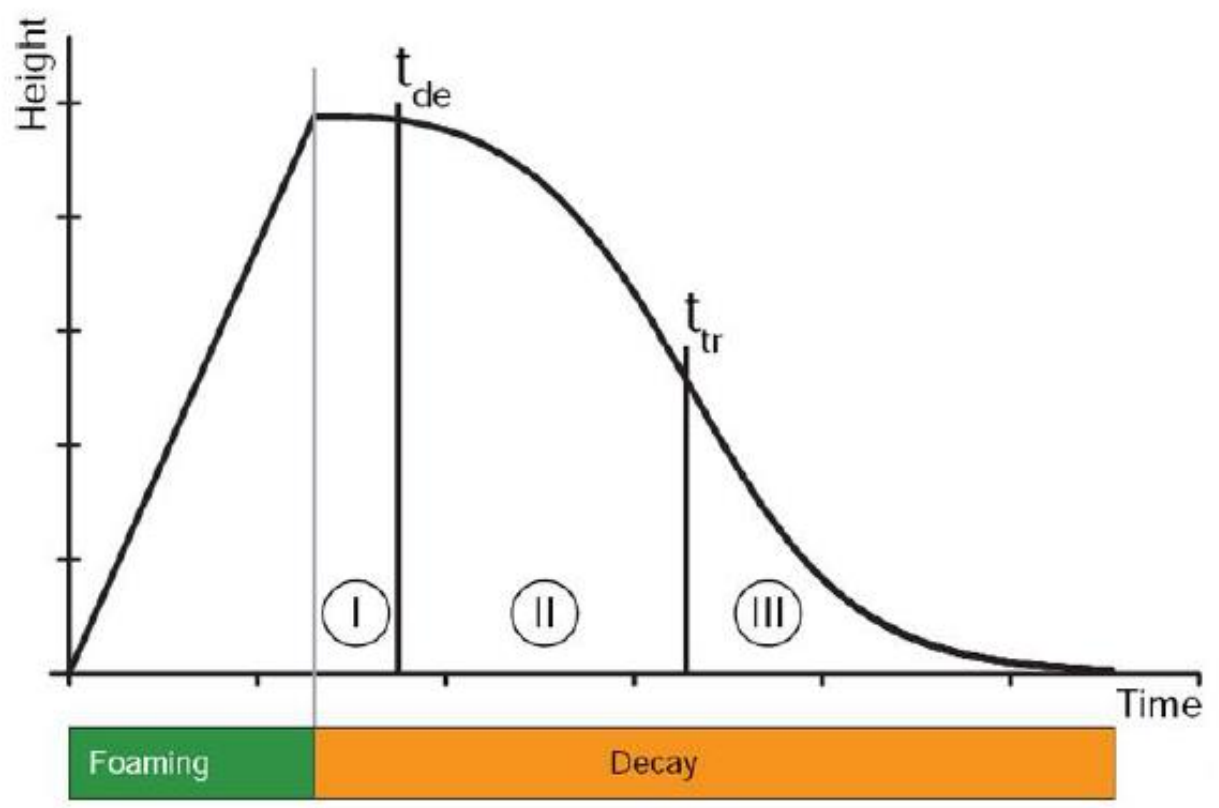

Figure 2. Foam stability phase diagram [5].

Figure 3 illustrates the foam stability without and with addition of SNP for various surfactant concentrations of AOS for 60 minutes' duration. The figure shows that foam height dropped rapidly at 5 min after the flow of $\mathrm{CO}_{2}$ gas from valve (V1) was shut off. Without SNP, the foam height reduced abruptly after 5 minutes as compared with other samples that have the addition of SNP. Foams stabilized by using AOS alone were unstable and difficult to maintain for long term [35]. Generally, the foam stability increased with increasing amount of AOS from 0.1 to $0.3 \mathrm{wt} \%$ but reduced a little bit at $0.5 \mathrm{wt} \%$ AOS except for the case of $0.3 \mathrm{wt} \%$ addition of SNP. $\mathrm{CO}_{2}$ foams stability improved when the surfactant concentration increase [36]. Foams generated at higher surfactant concentration basically have thicker foam lamellae that are more stable than thinner lamellae [37]. Interfacial tension (IFT) reduction also occurs, which assists in bubble generation and reduce the capillary pressure leading to slower drainage rate of the lamella [25].

The addition of $0.3 \mathrm{wt} \%$ SNP depicted the most stable foam of $32 \mathrm{~cm}$ foam height at $0.5 \mathrm{wt} \%$ AOS with increasing trend of different concentration of AOS. However, the addition of $0.5 \mathrm{wt} \%$ SNP at $0.5 \mathrm{wt} \%$ AOS, decreased the stability of the foam. Mohd et al. [18] have found the most stable foam achieved at $0.4 \mathrm{wt} \%$ nanoparticle, slightly higher than this finding possibly due to combination effect with surfactant as foaming agent during the investigation. While [22] claimed that stable $\mathrm{CO}_{2}$ foam could only be generated at SNP concentrations ranging from $0.3 \mathrm{wt} \%$ to 0.5 wt $\%$ at $1000 \mathrm{ppm}$ AOS concentration for $15 \mathrm{~nm}$ SNP. The presence of SNP provided longer lasting foam as it could strengthen the lamella. Higher SNP concentrations lead to more stable foam due to attachment of more particles spreading along the foam film interface [38]. However, the foam generated was unstable when excessive SNP concentration exceeded its optimum concentration used at $0.5 \mathrm{wt} \%$ based on the experimental condition $[18,39]$. The increase of SNP concentrations has led the accumulation of particles at the interface, resulting in particles aggregation. The formation of foam will be prohibited as the particles aggregation at foam film surface inducing the film to rupture [40, 41]. 


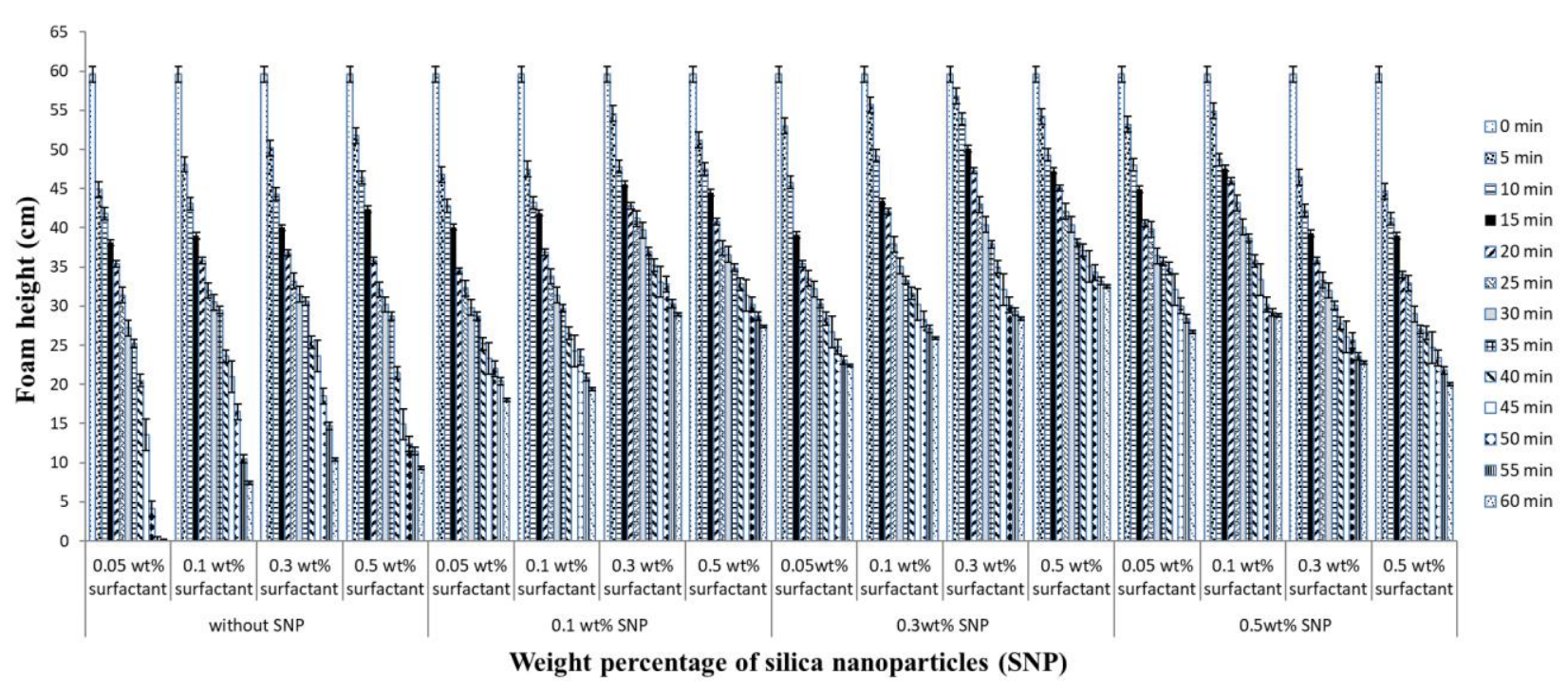

Figure 3. Foam stability in different concentrations of AOS and silica nanoparticles.

Possible mechanism of liquid file stabilization by surfactant and nanoparticle is illustrated in Figure 4 as proposed by Xue et al. [25]. Surfactant is likely adsorbed on the SNPs surfaces, resulting in lower hydrophilicity and increase in the interfacial activity. Synergistic interactions between the surfactant and SNPs led to enhancing the foam viscosity and stability. Basically, foams containing solid particle is more stable compared to surfactant alone because solid particle can minimize the contact area between oil and water [35, 42], resulting in a strict barrier formation that prevents droplet coalescence. Contrary to surfactant molecules, solid particle generally adsorbs irreversibly at the interface [1]. Low concentration of SNP will lead to lower adsorption rate of particle on bubble surface. Besides that, SNP has higher adhesion energy to the fluid compare to the AOS, which it gives the high potential for silica nanoparticle to stabilize the foams longer than AOS alone [1]. The stronger particle detachment energy, the more force is required to interrupt layers between particles and to make coalescence occurs [17].

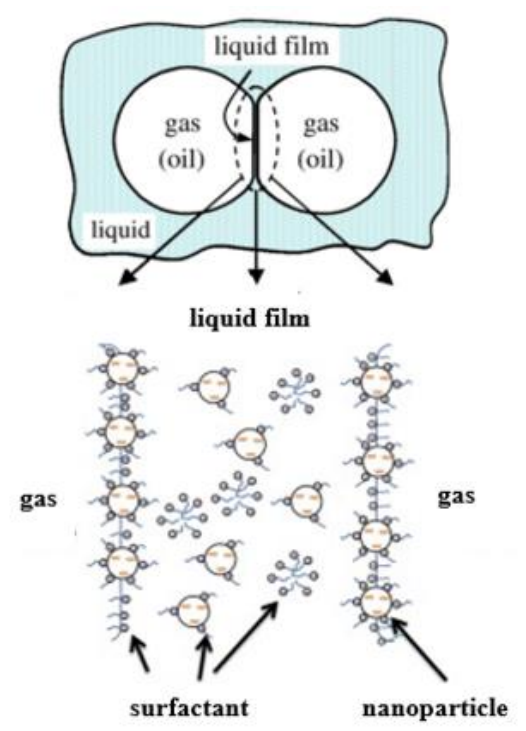

Figure 4. Possible mechanism of liquid film stabilization by surfactant and nanoparticle [14, 25]. Effect of Brine on Foam Stability 
Figure 5 shows the result of foams stability for different concentration of AOS in $0.1 \mathrm{wt} \%, 1 \mathrm{wt} \%$ and $5 \mathrm{wt} \%$ concentrations of brine without the addition of SNP. This study was conducted for analyzing the effect of brine salinity towards $\mathrm{CO}_{2}$ foams. At low concentration of AOS i.e. $0.1 \mathrm{wt} \%$ in $0.1 \mathrm{wt} \%$ of brine, the foams were unstable and dropped rapidly after 30 minutes, while at high concentration of AOS i.e. $0.5 \mathrm{wt} \%$ in $0.1 \mathrm{wt} \%$ concentration of brine, the foam remains stable. Generally, the foam heights increased with increasing amount of AOS concentrations for all concentrations of brine. Foam heights for all different concentrations of AOS in $1 \mathrm{wt} \%$ concentration of brine depicted the similar pattern over the same period of time. The most stable foams formed at concentration of $0.5 \mathrm{wt} \%$ AOS in $1 \mathrm{wt} \%$ of brine. The foam height decreased slowly and almost stable at $\mathrm{t}=60$ minutes. While, foams stability for $5 \mathrm{wt} \%$ concentration of brine in $0.1,0.3$ and $0.5 \mathrm{wt} \%$ of AOS were less stable as compared to foams stability at concentration of 1 wt $\%$ of brine.

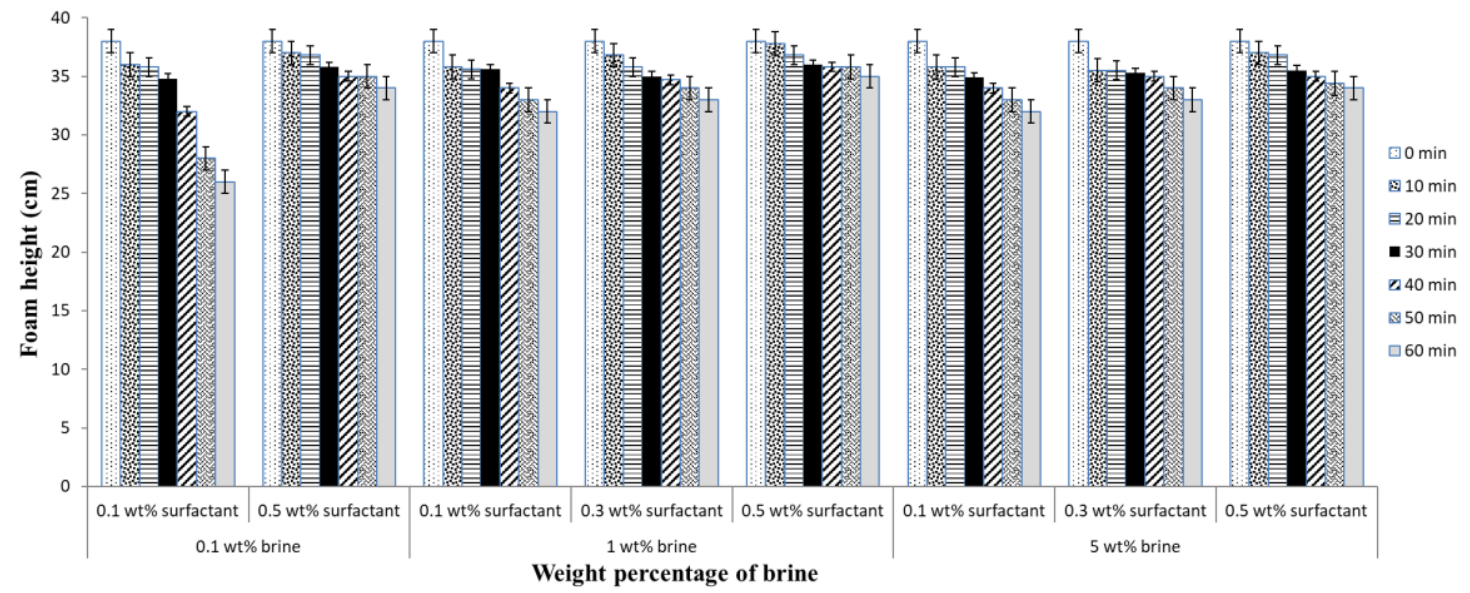

Figure 5. Foam stability for different concentration of AOS in different concentrations of brine without the addition of SNP.

For three different concentrations of brine, the most stable foams formed at concentration of 1 $\mathrm{wt} \%$ of brine. Basically, adding brine to the solution increases the foam stability but the increase of brine concentration up to $1 \mathrm{wt} \%$ have led to harder foam generation and the lamella was easily ruptured. Increase of brine concentrations reduced the foams stability due to increasing electrolyte i.e. $\mathrm{Na}^{+}$ions in the solutions. The salt's buffering effect has reduced the electrostatic repulsion, resulting in lower foam stability [21]. The results were almost comparable with those findings from $[18,21,43]$ which conclude that excessive addition of brine concentration inhibited the foam generation. The possible differences were due to different range of brine concentration as well as the selected points investigated between those researchers, leading to a shift in brine concentration limit. Thus, the presence of electrolytes in aqueous solution could reduce the foam stability when exist in excess concentration. The initial increase in foam stability with brine concentration was due to the reduction of hydrophobic force, while electrostatic force reduction due to double-layer compression led to the subsequent decrease beyond the maximum [44].

Separate measurement of foam stability was conducted for the best conditions as the results obtained from Figures 3 and 5 whereby at $1 \mathrm{wt} \%$ of brine, $0.5 \mathrm{wt} \%$ of AOS and $0.3 \mathrm{wt} \%$ of SNP, the most stable foams formed as shown in Figure 6. Aarra et al. [45] found that the brine composition and ionic strength did not significantly affect the height of foam column. Thus, addition of $0.3 \mathrm{wt} \%$ of SNP has stabilized the foam system at the initial stage by coating the formation of thinning film, resulting in stronger foam by the oscillatory structural force based on mechanism proposed by [14]. However, after 35 minutes the stability of the foams for sample without SNP was better than the one with $0.3 \mathrm{wt} \%$ SNP. Somehow in this case, it was found that the brine condition enhanced the foam stability without SNP that might be due to the addition of $\mathrm{Na}+$ ions. The presence of these ions may disturb the adsorption of SNP on the air-water interface. 
Adding brine to a solution with dispersed SNP can reduce the foam stability due to decrease in particles' electrostatic repulsion [21].

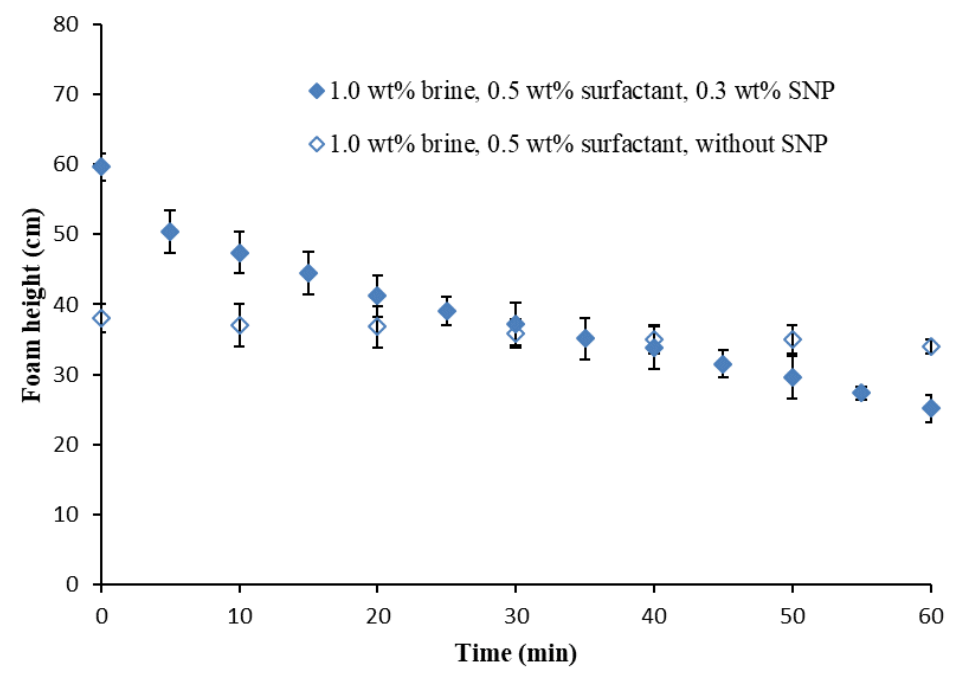

Figure 6. Effect of adding $1 \mathrm{wt} \%$ brine towards the foam stability for different concentration of SNP.

Figure 7 illustrates the microscopic images of the foams for three samples of foams conditions. The figure shows that bubbles are in circular shape at initial stage, which could break down to form polyhedral foams [42]. Foams formed with $0.5 \mathrm{wt} \%$ AOS were highly consisted of small size of bubbles (Figure 7 (a)) as compared to others. With the addition of $0.3 \mathrm{wt} \% \mathrm{SNP}$, the foams sizes were almost uniform in Figure 7 (b). However, the size of foams was the largest when the bubbles formed in $1 \mathrm{wt} \%$ of brine. The bigger the bubble size, more rapid the foam drainage to occur that leads to decreasing the foam stability. Next, the collapse stage occurred. There are two reasons for foam breaking phenomenon: (1) merging of small bubbles to form and expand larger bubbles, and (2) bubble walls are thinned. Due to higher pressure inside the smaller bubble, the interaction between bubbles with different sizes leads to dispersion of the higher pressure one to the liquid phase between the bubbles walls. This continues and results in coalescence of the bubbles to form a larger bubble [46]. The foam bubble reaching the transition stage could survive longer exceeding one hour [47]. Thus, addition of $1 \mathrm{wt} \%$ brine to the foam system has lower stability with higher bubble size, while $0.5 \mathrm{wt} \%$ AOS in water and those stabilized with $0.3 \mathrm{wt} \%$ SNP provided higher foam stability. The thickness of the foam film also plays role in foam stability as it depends on the surfactant concentration.

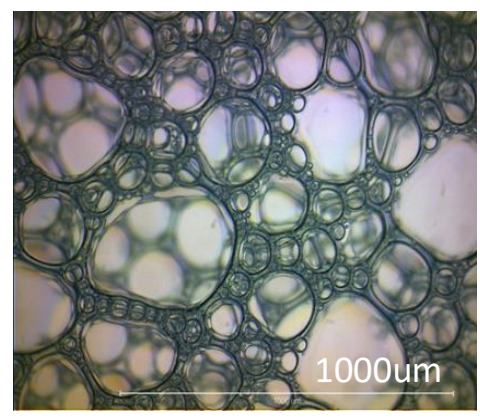

(a)

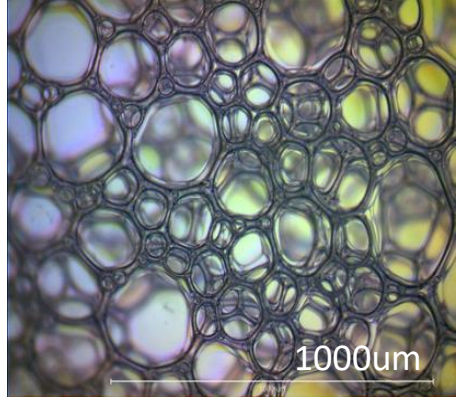

(b)

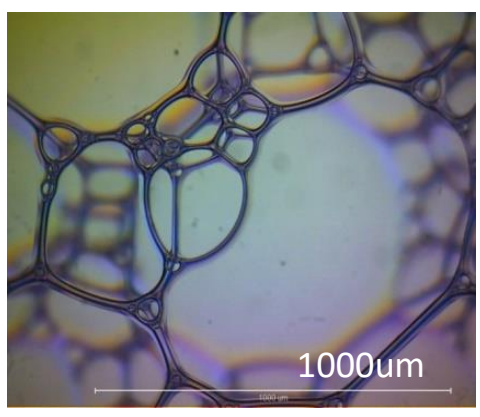

(c)

Figure 7. Formation of foams with (a) $0.5 \mathrm{wt} \%$ AOS in water, (b) $0.5 \mathrm{wt} \%$ AOS and $0.3 \mathrm{wt} \% \mathrm{SNP}$ in water and (c) $0.5 \mathrm{wt} \%$ AOS, $0.3 \mathrm{wt} \%$ SNP in $1 \mathrm{wt} \%$ brine. 


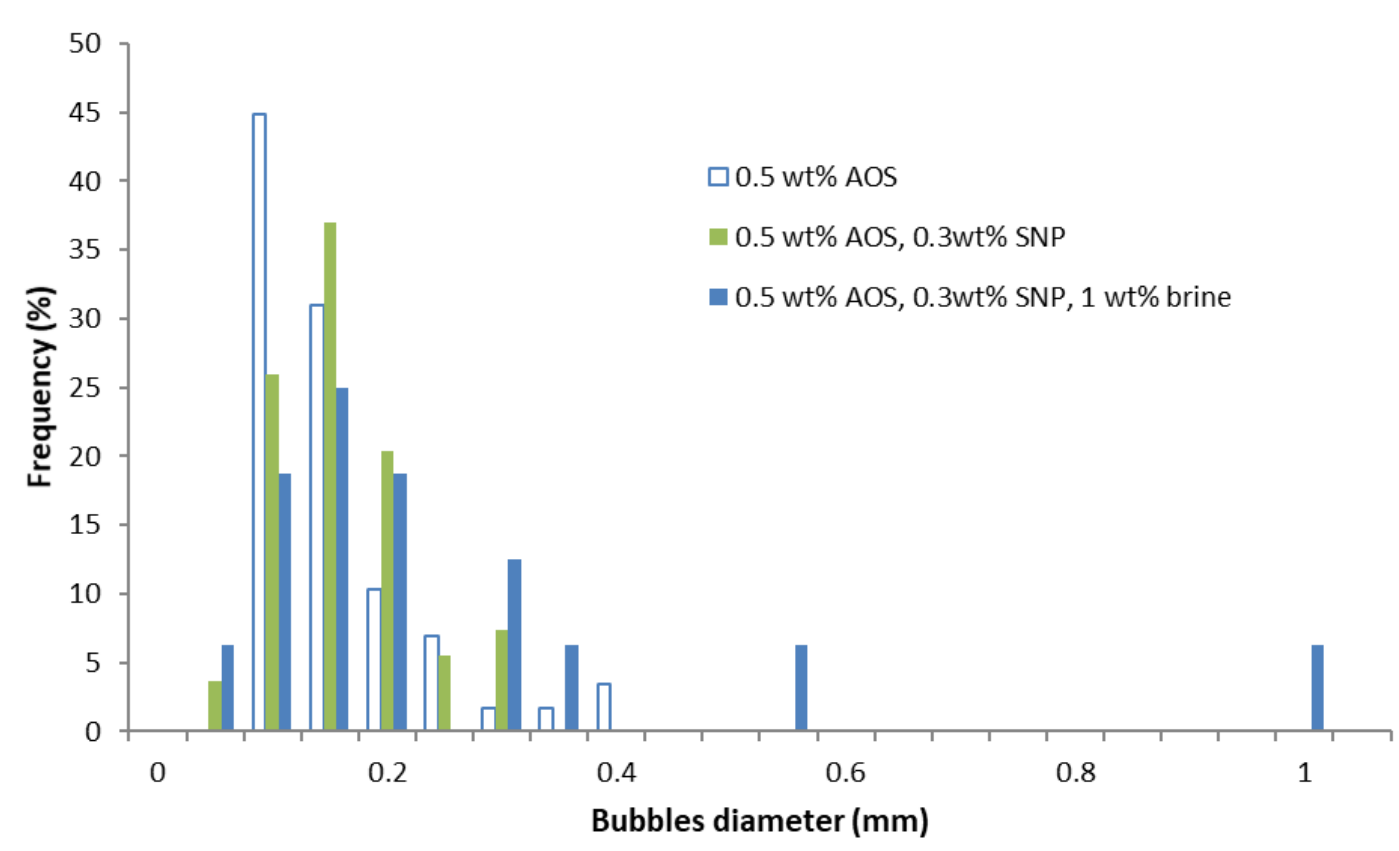

Figure 8. Bubble size distribution of (i) $0.5 \mathrm{wt} \%$ AOS in water, (ii) $0.5 \mathrm{wt} \%$ AOS and $0.3 \mathrm{wt} \% \mathrm{SNP}$ in water and (iii) $0.5 \mathrm{wt} \%$ AOS, $0.3 \mathrm{wt} \% \mathrm{SNP}$ in $1 \mathrm{wt} \%$ brine.

Figure 8 shows the size distribution of the bubbles in the foam samples. These values confirmed the conditions of foams formation as highlighted in Figure 7. The addition of 0.3 wt $\%$ SNP created more uniform bubbles size with average bubble diameter of $0.16 \mathrm{~mm}$. The average bubbles size shifted from $0.12 \mathrm{~mm}$ in the sample without SNP. With the addition of $1 \mathrm{wt} \%$ of brine, the average bubble size increased to $0.192 \mathrm{~mm}$.

\section{CONCLUSION}

Foam stability increased with increasing concentration of AOS surfactant. Relationship between surfactant concentration and SNP concentration with foam stability has been developed, which could be correlated with foam bubble size. The addition of $0.3 \mathrm{wt} \%$ SNP in $0.5 \mathrm{wt} \%$ AOS surfactant in water generated higher foam stability than the foam without SNP (AOS-water only). However, when the same condition of foam samples was applied for $0.5 \mathrm{wt} \%$ of SNP, the foam stability slightly decreased due to excessive concentration of SNP leading to accumulation of the particles at the interface that resulted in particles aggregation, causing the film to rupture. The addition of 0.3 $\mathrm{wt} \% \mathrm{SNP}$ and $0.5 \mathrm{wt} \%$ AOS surfactant in $1 \mathrm{wt} \%$ of brine also reduced the foam stability since adding brine to the solution with dispersed SNP can reduce the foam stability due to decrease in the particles' electrostatic repulsion. The bubble size produced at $0.5 \mathrm{wt} \%$ AOS, $0.3 \mathrm{wt} \% \mathrm{SNP}$ in $1 \mathrm{wt} \%$ brine was the largest, leading to more rapid of foam drainage to occur resulting in lower foam stability.

\section{ACKNOWLEDGEMENTS}

This work was supported by the Fundamental Research Grant Scheme (FRGS) (600-RMI/FRGS 5/3 (28/2013) and (600-RMI/FRGS 5/3 (95/2016) from Ministry of Higher Education (MoHE) to Universiti Teknologi MARA (UiTM). 


\section{REFERENCES}

[1] Bikerman JJ. Foams: theory and industrial applications, New Work. 1953.

[2] Bian Y, Penny GS, Sheppard NC. Surfactant formulation evaluation for carbon dioxide foam flooding in heterogeneous sandstone reservoir. SPE Improved Oil Recovery Symposium, Tulsa, Oklahoma. 2012.

[3] Schramm LL. Foams: fundamentals and applications in the petroleum industry (vol. 242), American Chemical Society. 1994.

[4] Roof JG. Snap-off of oil droplets in water-wet pores. Society of Petroleum Engineers Journal. 1970;10:85-90.

[5] Klaus L, Kazimierz M, Dipl-Ing WG, Dipl-Ing BM. Method and procedure for swift characterization of foamability and foam stability. Europian Union Patent. 2004.

[6] Dickson E, Ettelaie R, Kostakis T, Murray BS. Factors controlling the formation and stability of air bubble stabilized by partially hydrophobic silica nanoparticles. Langmuir. 2004;20:8517-8525.

[7] Chen Y, Elhag AS, Poon BM, Cui L, Ma K, Liao SY, Omar A, Worthen A, Hirasaki GJ, Nguyen QP, Johnston KP. Ethoxylated cationic surfactants for $\mathrm{CO}_{2}$ EOR in high temperature, high salinity reservoirs. SPE Improved Oil Recovery Symposium, Tulsa, Oklahoma. 2012.

[8] Dominika Z, Eva S, Eduardo G, Michele F, Libero L, Vincenzo B, Maria TB, Giorgio B, Francesca R. Nanoparticle laden interfacial layers and application to foams and solid foams. Colloids and Surfaces A: Physicochemical and Engineering Aspects. 2013;438:132-140.

[9] Binks BP, Horozov TS. Aqueous foams stabilized solely by silica nanoparticles. Angewandte Chemie- International Edition. 2005;44: 3722-3725.

[10] Worthen AJ, Bagaria HG, Chen Y, Bryant SL, Huh C, Johnston KP. Nanoparticle stabilized carbon dioxide in water foams for enhanced oil recovery. SPE Improved Oil Recovery Symposium, Tulsa, Oklahama, USA. 2012.

[11] Omar S, Jaafar MZ, Ismail AR, Sulaiman WRW. Relationship between foam stability and the generated electrokinetic signals during FAWAG (foam assisted water alternate gas) process. Journal of Applied Sciences. 2014;14:1123-1130.

[12] Mohd TAT, Jaafar MZ, Rasol AAA, Ali J. Review: a new prospect of streaming potential measurement in alkaline-surfactant-polymer flooding. Chemical Engineering Transactions. 2017;56:1183-1188.

[13] Mohd TAT, Jaafar MZ, Rasol AAA, Hamid MF. Measurement of streaming potential in downhole application: an insight for enhanced oil recovery monitoring. MATEC Web of Conferences. 03002. 2017.

[14] Horozov TS. Foams and foam stabilized by solid particles. Current Opinion in Colloid and Interface Science. 2008;13:134-140.

[15] Worthen AJ, Bryant SL, Huh C, Johnston KP. Carbon dioxide-in-water foams stabilized with nanoparticles and surfactant acting in synergy. AIChE Journal. 2013;59:3490-3501.

[16] Cui ZG, Cui YZ, Cui CF, Chen Z, Binks BP. Aqueous foams stabilized by in situ surface activation of $\mathrm{CaCO}_{3}$ nanoparticles via adsorption of anionic surfactant. Langmuir. 2010;26:12567-12574.

[17] Binks BP. Particles as surfactants-similarities and differences. Current Opinion in Colloid \& Interface Science. 2002;7:21-41.

[18] Mohd TAT, Muhayyidin AHM, Ghazali NA, Shahruddin MZ, Alias N, Arina S, Ismail SN, Ramlee NA. Carbon dioxide $\left(\mathrm{CO}_{2}\right)$ foam stability dependence on nanoparticle concentration for enhanced oil recovery (EOR). Applied Mechanics and Materials. 2014;548-549:18761880 . 
[19] Mohd TAT, Alias N, Ghazali NA, Yahya E, Sauki A, Azizi A, Yusof NM. Mobility investigation of nanoparticle-stabilized carbon dioxide foam for enhanced oil recovery (EOR). Advanced Materials Research. 2015;1119:90-95.

[20] Zhang S, Sun D, Dong X, Li C, Xu J. Aqueous foams stabilized with particles and nonionic surfactant. Colloids and Surfaces A: Physicochemical and Engineering Aspects. 2008;324:18.

[21] Espinoza DA, Caldelas FM, Johnston KP, Bryant SL. Nanoparticle-stabilized supercritical carbon dioxide foams for potential mobility control applications. SPE Improved Oil Recovery Symposium, Tulsa, Oklahama, USA. 2010.

[22] AttarHamed F, Zoveidavianpoor M, Jalilavi M. The incorporation of silica nanoparticle and alpha olefin sulphonate in aqueous $\mathrm{CO}_{2}$ foam: investigation of foaming behavior and synergistic effect. Petroleum Science and Technology. 2014;32:2549-2558.

[23] Rojas Y, Kakadjian S, Aponte A. Stability and rheological behavior of aqueous foams for underbalanced drilling. SPE International Symposium on Oilfield Chemistry, Houston, Texas. 2001.

[24] Mohd TAT, Baco J, Abu Bakar NF, Jaafar MZ. Effects of particle shape and size on nanofluid properties for potential enhanced oil recovery (EOR). MATEC Web of Conferences. 69, 03006. 2016.

[25] Xue Z, Worthen A, Qajar A, Robert I, Bryant S, Huh C, Prodanović M, Johnston KP. Viscosity and stability of ultra-high internal phase $\mathrm{CO}_{2}$-in-water foams stabilized with surfactants and nanoparticles with or without polyelectrolytes. Journal of Colloid and Interface Science. 2015;461:383-395.

[26] Singh R, Mohanty KK. Synergy between nanoparticles and surfactants in stabilizing foams for oil recovery. Energy Fuels. 2015;29:467-479.

[27] Ibrahim AF, Emrani A, Nasraldin $\mathrm{H}$. Stabilized $\mathrm{CO}_{2}$ foam for EOR applications. Carbon Management Technology Conference, Houston, Texas, USA. 2017.

[28] San J, Wang S, Yu J, Liu N, Lee R. Nanoparticle-stabilized carbon dioxide foam used in enhanced oil recovery: effect of different ions and temperatures. SPEJ. Preprint. 179628-PA. 2017.

[29] Abdul Hamid K, Azmi WH, Mamat R, Usri NA, Najafi G. Effect of temperature on heat transfer coefficient of titanium dioxide in ethylene glycol-based nanofluid. Journal of Mechanical Engineering and Sciences. 2015;8: 1367-1375.

[30] Sahid NSM, Rahman MM, Kadirgama K, Maleque MA. Experimental investigation on properties of hybrid nanofluids $\left(\mathrm{TiO}_{2}\right.$ and $\left.\mathrm{ZnO}\right)$ in water-ethylene glycol mixture. Journal of Mechanical Engineering and Sciences. 2017;11(4): 3087-3094.

[31] Abdullah A, Mohamad IS, Bani Hashim AY, Abdullah N, Wei PB, Md. Isa MH, Zainal Abidin S. Thermal conductivity and viscosity of deionised water and ethylene glycol-based nanofluids. Journal of Mechanical Engineering and Sciences. 2016;10(3): 2249-2261.

[32] Zakaria I, Michael Z, Mohamed WANW, Mamat AMI, Azmi WH, Mamat R, Saidur R. A review of nanofluid adoption in polymer electrolyte membrane (PEM) fuel cells as an alternative coolant. Journal of Mechanical Engineering and Sciences. 2015;8: 1351-1366.

[33] Ismail S, Lockman Z, Kian TW. Formation and photoelectrochemical properties of $\mathrm{TiO}_{2}$ nanotube arrays in fluorinated organic electrolyte. Journal of Mechanical Engineering and Sciences. 2017;11(4): 3129-3136.

[34] Mohd TAT, Razman, HIM, Jarni HH, Yahya E, Jaafar MZ. Potential of polymeric surfactant in stabilizing carbon dioxide foam for enhanced oil Recovery. Chemical Engineering Transactions. 2018;66:655-660.

[35] Blute I, Pugh RJ, Pas JVD, Callaghan I. Silica nanoparticle sols 1. Surface chemical characterization and evaluation of the foam generation (foamability). Journal of Colloid and Interface Science. 2007;313:645-655. 
[36] Hanssen JE, Dalland M. Foams for effective gas blockage in the presence of crude oil. SPE/DOE Enhanced Oil Recovery Symposium, Tulsa, Oklahoma. 1990.

[37] Farajzadeh R, Krastev R, Zitha PLJ. Foam films stabilized with alpha olefin sulfonate (AOS). Colloids and Surfaces A: Physicochemical and Engineering Aspects. 2008;324:3540.

[38] Mo D, Yu J, Liu N, Lee R. Study of the effect of different factors on nanoparticle-stabilized $\mathrm{CO}_{2}$ foam for mobility control. SPE Annual Technical Conferences and Exhibition. San Antonio, Texas, USA. 2012.

[39] Worthen AJ, Bagaria HG, Chen Y, Bryant SL, Huh C, Johnston KP. Nanoparticle-stabilized carbon dioxide-in-water foams with fine texture. Journal of Colloid and Interface Science. 2012;391:142-151.

[40] Yu J, An C, Mo D, Liu N, Lee RL. Foam mobility control for nanoparticle-stabilized supercritical $\mathrm{CO}_{2}$ foam. SPE Improved Oil Recovery Symposium, Tulsa, Oklahoma, USA. 2012.

[41] Mohd TAT, Shukor MAA, Ghazali NA, Alias N, Yahya E, Azizi A, Shahruddin MZ, Ramlee NA. Relationship between foamability and nanoparticle concentration of carbon dioxide $\left(\mathrm{CO}_{2}\right)$ foam for enhanced oil Recovery (EOR). Applied Mechanics and Materials. 2014;548-549:67-71.

[42] Emrani AS, Nasr-el-din HA. Stabilizing $\mathrm{CO}_{2}$-foam using nanoparticles. SPE European Formation Damage Conference and Exhibition, Budapest, Hungary. 2015.

[43] Yu J, Liu N, Li L, Lee R. Generation of nananoparticle-stabilized supecritical carbon dioxide foams. Carbon Management Technology Conference. CMTC 150849. 2012.

[44] Wang L, Yoon RH. Effects of surface forces and film elasticity on foam stability. International Journal of Mineral Processing. 2008;85:101-110.

[45] Aarra MG, Ormehaug PA, Skauge A, Masalmeh SK. Experimental study of $\mathrm{CO}_{2^{-}}$and methane- foam using carbonate core material at reservoir conditions. SPE Middle East Oil and Gas Show and Conference. 2011.

[46] Eren T. Foam characterization: bubble size and texture effects. MSc thesis, Petroleum and Natural Gas Engineering Department, Middle East Technical University. 2004.

[47] Enick RM, Olsen DK. Mobility and conformance control for carbon dioxide enhanced oil recovery $\left(\mathrm{CO}_{2}\right.$-EOR) via thickeners, foams, and gels-a detailed literature review of 40 years of research. Contract DE-FE0004003. Activity. 4003(01). 2012. 